\author{
강우빈도해석에서 Bootstrap을 이용한 확률분포의 \\ 매개변수 추정에 대한 불확실성 해석 \\ 서영민 · 박기범 $)^{*}$ \\ 영남대학교 토목공학과, ${ }^{1)}$ 동양대학교 철도토목과 \\ (2010년 9월 27일 접수; 2010년 11월 23일 수정; 2011년 1월 13일 채택)
}

\title{
Uncertainty Analysis for Parameter Estimation of Probability Distribution in Rainfall Frequency Analysis Using Bootstrap
}

\author{
Young Min Seo, Ki Bum Park \\ Department of Civil Engineering, Yeungnam University Kyeungsan 721-749, Korea \\ 1) Department of Railroad and Civil Engineering, Dongyang University, Kyeongbuk 750-711, Korea \\ (Manuscript received 27 Sepember, 2010; revised 23 November, 2010; accepted 13 January, 2011)
}

\begin{abstract}
Bootstrap methods is the computer-based resampling method that estimates the standard errors and confidence intervals of summary statistics using the plug-in principle for assessing the accuracy or uncertainty of statistical estimates, and the BCa method among the Bootstrap methods is known much superior to other Bootstrap methods in respect of the standards of statistical validation. Therefore this study suggests the method of the representation and treatment of uncertainty in flood risk assessment and water resources planning from the construction and application of rainfall frequency analysis model considersing the uncertainty based on the nonparametric BCa method among the Bootstrap methods for the assessement of the estimation of probability rainfall and the effect of uncertainty considering the uncertainty of the parameter estimation of probability in the rainfall frequency analysis that is the most fundamental in flood risk assessement and water resources planning.
\end{abstract}

Key Words : Rainfall frequency analysis, Probability distribution, Parameter, Uncertainty, Bootstrap

\section{1. 서 론}

홍수위험관리에 있어서 홍수위험평가 및 의사결정 시 위험도와 불확실성은 매우 중요하나 불확실성에 대한 설명이 충분하지 않은 것이 현실이다. 특히, 홍수 위험평가를 위한 모델선정 및 실행, 매개변수의 선택

${ }^{*}$ Corresponding author : Ki Bum Park, Department of Railroad and Civil Engineering, Dongyang University, Kyeongbuk 750-711, Korea

Phone: +82-53-321-1517

E-mail: pkb5032@naver.com
또는 홍수량 추정치와 관련된 불확실성의 고려없이 일반적으로 확정론적 모델링을 이용하고 있으며, 또 한 충분한 토론, 정책결정 및 의사결정은 확정론적 모 델링 결과를 근거로 이루어지고 있는 실정이다.(서 등, 2009a, 2009b)

강우빈도해석은 통계학적 결과의 정확성 또는 불 확실성은 표본 통계치 또는 확률분포의 매개변수에 대한 표본분포(표집분포, sampling distribution)에 기 초하며, 표본분포는 모집단으로부터의 많은 무작위 표본으로부터 추정된다. 이러한 통계학적 추정에서 
정확도 또는 불확실성을 평가하기 위한 척도로는 표 준오차, 편향성, 예측오차 및 신뢰구간 등이 있으며, 이 중 표준오차는 통계학적 정확성 또는 불확실성을 나타내는 가장 일반적인 방법이다. 표준오차에 대한 대부분의 이론적 공식들은 정규이론에 근거한 근사식 이다. 일반적인 통계학적 해석에서 매개변수적 가정 을 전제로 하는 주된 이유는 그것이 표준오차에 대한 공식을 유도하는데 수학적으로 매우 용이하기 때문이 다. 또한 표준오차는 표본의 크기가 매우 커짐에 따라 표본평균의 분포가 근사적으로 정규분포를 따르는 중 심극한정리에 근거하기 때문에 대표본에 대해서는 우 수한 추정치를 제공할 수 있으나, 소표본에 대해서는 그 추정의 정확도가 떨어지기 때문에 항상 중심극한 정리가 유용한 것만은 아닌 단점을 가지게 된다(Efron 과 Tibshirani, 1994).

이와는 달리 Bootstrap 기법은 통계학적 추정치의 정확도를 평가하기 위한 컴퓨터 기반 리샘플링 기법 (resampling method)으로서 플러그인 원칙(plug-in principle)을 이용하여 요약통계치의 표준오차를 추정 하고, 표준오차에 대한 Bootstrap 추정치는 이론적 계 산이 많이 요구되지 않기 때문에 추정치에 대한 수학 적 복잡성에 상관없이 사용가능한 장점을 가진다 (DiCiccio와 Efron, 1996; Efron, 2003). 이러한 Bootstrap 기법에는 Bootstrap-t 기법, 퍼센타일 기법 (percentile method), $\mathrm{BCa}$ 기법(Bias-Corrected 와 Accelerated method) 및 $\mathrm{ABC}$ 기법(Approximate Bootstrap Confidence intervals) 등이 있으며, 이 중 $\mathrm{BCa}$ 기법 및 $\mathrm{ABC}$ 기법은 표준, Bootstrap-t 및 퍼센 타일 기법보다 적합도 기준면에서 훨씬 우수한 결과 를 나타내는 것으로 알려져 있다(Efron과 Tibshirani, 1994; Dunn, 2001). 또한, 극한강우를 고려한 강우빈 도해석을 위하여 SIR 알고리즘과 Bootstrap을 결합한 방식을 하여 리샘플링 과정의 불확실성을 정량화하였 으나(문 등 2010), 본 연구에서는 Bootstrap 기법중 신 뢰구간 추정에 있어 편의를 수정함으로 해서 신뢰구 간 추정의 정확도가 높은 것으로 알려져 있는 $\mathrm{BCa}$ 기 법을 적용하였음.

따라서 본 연구에서 홍수위험평가 및 강우빈도해 석에서 확률분포의 매개변수 추정에 대한 불확실성 고려한 확률강우량의 산정과 불확실성의 영향을 평가
하기 위하여 Bootstrap 기법 중 $\mathrm{BCa}$ 기법에 기반한 불 확실성을 고려한 강우빈도해석모델 구축 및 적용을 통해 홍수위험평가 및 수자원 계획 등에 있어서 불확 실성 표현 및 처리기법을 제시하였다.

\section{2. $\mathrm{BCa}$ 기법}

$\mathrm{BCa}$ 기법은 퍼센타일 기법을 개선한 기법으로서 $\mathrm{BCa}$ 신뢰구간 $\mathrm{BCa}$ interval)의 양 끝점은 퍼센타일 기법과 마찬가지로 Bootstrap 분포의 퍼센타일로 주 어지며, 퍼센타일은 가속인자(acceleration) $\hat{a}$ 와 편의 수정인자(bias-correction) $\hat{z}_{0}$ 에 의해 결정된다. 그리 고 Monte Carlo 표집오차(표본추출오차, sampling error)를 충분히 감소시키기 위해서는 적어도 1,000 개 이상의 Bootstrap 추정치(Bootstrap replication)가 요 구된다(Efron 와 Tibshirani, 1994). BCa 기법은 매개 변수적 $\mathrm{BCa}$ 기법(parametric $\mathrm{BCa}$ method) 및 비매개 변수적 $\mathrm{BCa}$ 기법(nonparametric $\mathrm{BCa}$ method)으로 크게 구분할 수 있으며, 본 연구에서는 비매개변수적 $\mathrm{BCa}$ 기법을 적용하였다.

\section{1. 비매개변수적 $\mathrm{BCa}$ 기법}

$\mathrm{BCa}$ 기법에서 포함확률(coverage) 1-2a에 대한 $\mathrm{BCa}$ 신뢰구간은 식 (1)과 같다(Efron와 Tibshirani, 1994).

$$
\begin{aligned}
& \left(\hat{\theta}_{l o}, \hat{\theta}_{u p}\right)=\left(\hat{\theta}^{*\left(\alpha_{1}\right)}, \hat{\theta}^{*\left(\alpha_{2}\right)}\right) \\
& \alpha_{1}=\Phi\left(\hat{z}_{0}+\frac{\hat{z}_{0}+z^{(\alpha)}}{1-\hat{a}\left(\hat{z}_{0}+z^{(\alpha)}\right)}\right) \\
& \alpha_{2}=\Phi\left(\hat{z}_{0}+\frac{\hat{z}_{0}+z^{(1-\alpha)}}{1-\hat{a}\left(\hat{z}_{0}+z^{(1-\alpha)}\right)}\right)
\end{aligned}
$$

여기서, $\mathrm{a}$ 는 유의수준, $\Phi(\cdot)$ 는 누가표준정규분포함 수, $z^{(\alpha)}$ 는 표준정규분포의 $100 \mathrm{a}$ 번째 퍼센타일이고 $\hat{\theta}_{l o}$ 및 $\hat{\theta}_{u p}$ 는 $\hat{\theta}$ 의 하한 및 상한이다. 만약 식 (2) and (3)으 로부터 $\quad \hat{a}=0, \quad \hat{z}_{0}=0$ 이면, $\quad \alpha_{1}=\Phi\left(z^{(\alpha)}\right)=\alpha, \alpha_{2}=$ $\Phi\left(z^{(1-\alpha)}\right)=1-\alpha$ 가 되어 $\mathrm{BCa}$ 신뢰구간과 퍼센타일 신 뢰구간은 동일한 결과를 나타내게 되며, $\mathrm{BCa}$ 기법은 $\hat{a}$ 와 $\hat{z}_{0}$ 의 값에 의해 표준 및 퍼센타일 신뢰구간의 결 점을 보완하게 된다. 
편의수정인자 $\hat{z}_{0}$ 는 원추정치(original estimate) $\hat{\theta}$ 보다 작은 Bootstrap 추정치 $\hat{\theta}^{*}$ 의 비율로서 식 (4)와 같이 나타낼 수 있다.

$$
\hat{z}_{0}=\Phi^{-1}\left(\frac{\#\left\{\hat{\theta}^{*}(b)<\hat{\theta}\right\}}{B}\right)
$$

여기서, $\Phi^{-1}(\cdot)$ 는 표준누가정규분포의 역함수이고 $B$ 는 Bootstrap 표본 발생수이다. $\hat{z}_{0}$ 는 $\hat{\theta}^{*}$ 의 중앙값 편의(median bias)이며, $\hat{\theta}^{*}(b)$ 수의 절반이 정확하게 $\hat{\theta}$ 보다 작을 경우에는 $\hat{z}_{0}=0$ 가 된다.

가속인자 $\hat{a}$ 는 매개변수의 참값 $\theta$ 에 대한 $\hat{\theta}$ 의 표준 오차의 변화율을 나타내며, $\hat{\theta}=s(\boldsymbol{X})$ 에 대한 Jackknife 값을 이용한다. $\boldsymbol{X}_{(i)}$ 를 $i$ 번째 값 $x_{i}$ 가 제거된 원표본 (original sample)이라고 하면 $n$ 세트 $(n$ : 원자료수)의 Jackknife 표본을 이용한 추정치는 $\hat{\theta}_{(i)}=s\left(\boldsymbol{X}_{(i)}\right)$ 이 고 $n$ 세트의 Jackknife 표본으로부터 추정된 추정치 의 평균은 $\hat{\theta}_{(\cdot)}=\frac{1}{n} \sum_{i=1}^{n} \hat{\theta}_{(i)}$ 이 되며, 가속인자 $\hat{a}$ 는 식 (5)와 같이 나타낼 수 있다.

$$
\hat{a}=\frac{\sum_{i=1}^{n}\left(\hat{\theta}_{(\cdot)}-\hat{\theta}_{(i)}\right)^{3}}{6\left\{\sum_{i=1}^{n}\left(\hat{\theta}_{(\cdot)}-\hat{\theta}_{(i)}\right)^{2}\right\}^{3 / 2}}
$$

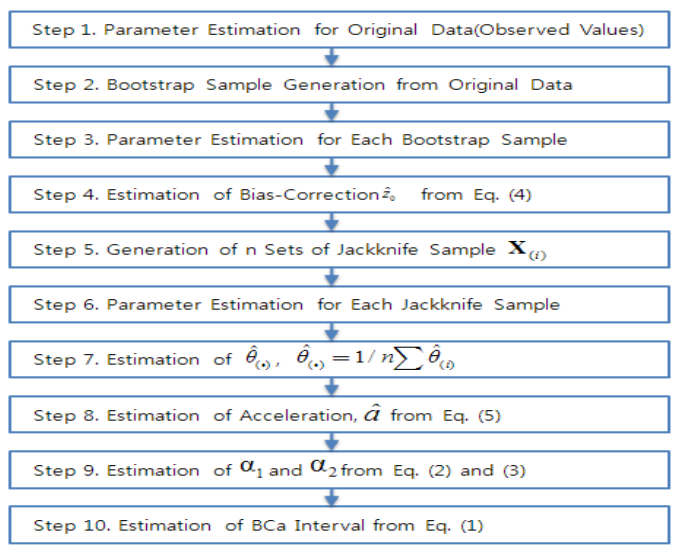

Fig. 1. Algorithm of BCa Method.

\section{2. $\mathrm{BCa}$ 신뢰구간 산정을 위한 알고리즘}

비매개변수적 $\mathrm{BCa}$ 기법을 이용한 신뢰구간 산정 알고리즘(Efron와 Tibshirani, 1994) 및 모식도는 Fig. 1 와 Fig. 2 와 같다.

\section{3. 결과 및 고찰}

\section{1. 적용유역 및 분석개요}

본 연구에서는 강우빈도해석에서 확률분포의 매개 변수 추정에 대한 불확실성을 고려한 확률강우량의 산정 및 불확실성의 영향을 평가하기 위하여 비매개 변수적 $\mathrm{BCa}$ 기법에 기반한 강우빈도해석모델 구축하 였다. 확률분포의 매개변수 추정기법으로는 L-moment 법(Rao와 Hamed, 2000)을 이용하였으며, 적합도 검 정을 위해 Chi-Square 및 Kolmogorov- Smirnov 검정 을 적용하였다. 그리고 강우빈도분석 및 Bootstrap 알 고리즘의 구현을 위하여 $\mathrm{C}$ 언어를 이용하였다.

모델의 적용성을 평가하기 위하여 위천 유역 내 의 성(기상청, 위도 $36^{\circ} 21^{\prime}$, 경도 $128^{\circ} 41^{\prime}$, 표고 EL. $\left.81.1 \mathrm{~m}\right)$ 지점(Fig. 3)의 1973 2007년(35년) 동안의 시우량 자 료를 수집하여 분석에 사용하였으며, 먼저 시우량 자 료의 이상치, 결측치 등을 보정하고 지속시간별 최대 강우량 산정에 필요한 강우사상을 추출하였다. 다음 으로 추출된 강우사상으로부터 지속시간별 최대강우 량을 산정하고 이로부터 10,000 세트의 Bootstrap 표 본을 발생시킨 후 각 Bootstrap 표본에 대하여 L-moment 법을 이용하여 각 확률분포의 매개변수를

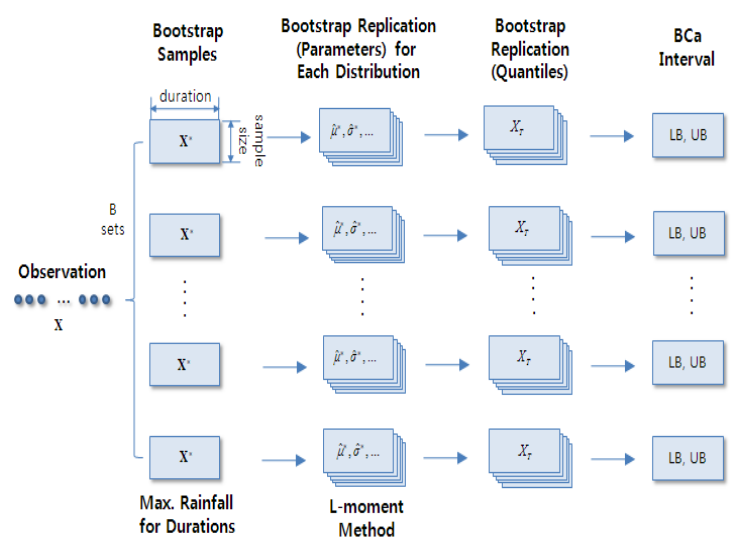

Fig. 2. Schematic of BCa Method. 
추정하였다. 그리고 추정된 매개변수로부터 각 확률 분포에 대한 확률강우량을 추정하였으며, 이때 매개 변수의 적합성 체크 및 각 확률분포에 대한 적합도 검 정을 통해 1 차적으로 최적 확률분포형을 필터링하였 으며, 1 차로 선정된 확률분포형을 대상으로 확률강우 량에 대한 Bootstrap 추정치들로부터 표준오차 및 변 동계수를 산정하여 Bootstrap 추정치의 변동성이 가 장 낮은 확률분포형을 2 차적으로 필터링하여 최적 확 률분포형을 선정하였다.

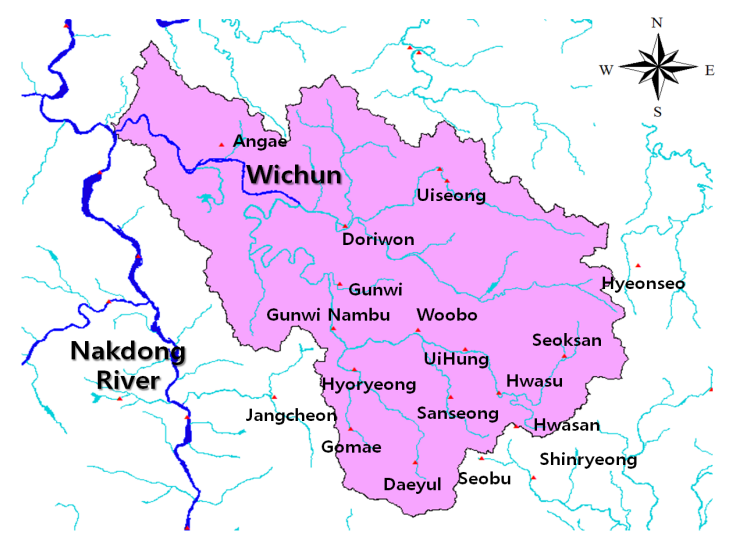

Fig. 3. Study Area and Location of Raingauges.

\section{2. $\mathrm{BCa}$ 기법의 적용 및 고찰}

앞서 설명한 바와 같이 본 연구에서는 매개변수의 적합성 체크 및 각 확률분포에 대한 적합도 검정을 통 해 1 차적으로 최적 확률분포형을 필터링하였으며, 1 차로 선정된 확률분포형을 대상으로 확률강우량에 대 한 Bootstrap 추정치들로부터 표준오차 및 변동계수 를 산정하여 Bootstrap 추정치의 변동성이 가장 낮은 확률분포형을 2 차적으로 필터링하여 최적 확률분포 형을 선정하였다.

그 결과 확률분포형의 적합도 순위는 General Logistic 분포(GLO), General Extreme 분포(GEV) 및 Weibull 분포의 순으로 분석되었으며, 선정된 각 분 포형에 대한 지속시간 24시간에서의 재현기간별 Bootstrap 추정치에 대한 요약통계치는 Table 1 3과 같고 재현기간 증가에 따른 변동계수 및 표준오차의 변화는 Fig. 4과 같이 분석되었다. 또한 선정된 확률분 포형별 확률강우량에 대한 $\mathrm{BCa}$ 신뢰구간을 추정하여 그 결과를 Table 4 6에 정리하였으며, Fig. 5 와 같이 도식적으로 비교하였다.

먼저 Table 1 3 및 Fig. 4로부터 각 확률분포형의 Bootstrap 추정치에 대한 분석결과를 살펴보면 재현 기간이 증가함에 따라 표준오차 및 변동계수가 증

Table 1. Statistics of Bootstrap Replication for GEV Distribution (duration=24 hr)

\begin{tabular}{ccccccccccc}
\hline $\begin{array}{c}\text { Return } \\
\text { Period }\end{array}$ & Quantile & MIN & MEAN & MAX & SE & CV & $a_{1}$ & $a_{2}$ & LB & UB \\
\hline \hline 20 & 174.06 & 150.0 & 192.2 & 238.5 & 19.14 & 0.100 & 0.035 & 0.945 & 154.6 & 222.9 \\
\hline 30 & 189.24 & 153.7 & 207.5 & 259.2 & 23.61 & 0.114 & 0.027 & 0.934 & 159.7 & 246.8 \\
\hline 50 & 209.54 & 156.0 & 227.6 & 285.7 & 30.38 & 0.133 & 0.014 & 0.908 & 161.9 & 274.8 \\
\hline 80 & 229.48 & 157.6 & 247.0 & 323.0 & 37.88 & 0.153 & 0.018 & 0.918 & 166.4 & 305.6 \\
\hline 100 & 239.41 & 158.2 & 256.7 & 343.5 & 41.92 & 0.163 & 0.018 & 0.917 & 167.6 & 321.1 \\
\hline 200 & 272.28 & 159.7 & 288.3 & 415.8 & 56.68 & 0.197 & 0.022 & 0.926 & 171.2 & 372.2 \\
\hline 500 & 320.98 & 161.0 & 334.9 & 535.8 & 82.23 & 0.246 & 0.020 & 0.922 & 175.6 & 445.3 \\
\hline MIN : Minimum MAX : Maximum, SE : Standard Error, CV : Coefficient of variation, LB : Lower Bound, UB: Upper Bound
\end{tabular}

Table 2. Statistics Bootstrap Replication for Weibull Distribution (duration=24 hr)

\begin{tabular}{crrrrrrrrrr}
\hline $\begin{array}{l}\text { Return } \\
\text { Period }\end{array}$ & Quantile & MIN & MEAN & MAX & SE & CV & $a_{1}$ & $a_{2}$ & LB & UB \\
\hline \hline 20 & 175.38 & 143.1 & 191.3 & 231.2 & 20.99 & 0.110 & 0.038 & 0.949 & 153.1 & 224.7 \\
\hline 30 & 187.80 & 147.2 & 203.6 & 248.8 & 24.71 & 0.121 & 0.034 & 0.944 & 157.3 & 245.1 \\
\hline 50 & 203.08 & 151.8 & 218.5 & 275.6 & 29.59 & 0.135 & 0.031 & 0.940 & 162.2 & 265.4 \\
\hline 80 & 216.81 & 155.6 & 231.8 & 300.8 & 34.23 & 0.148 & 0.033 & 0.943 & 166.4 & 288.1 \\
\hline 100 & 223.24 & 157.3 & 238.0 & 312.8 & 36.48 & 0.153 & 0.030 & 0.939 & 168.3 & 297.6 \\
\hline 200 & 242.85 & 162.2 & 256.9 & 350.2 & 43.60 & 0.170 & 0.030 & 0.939 & 173.9 & 324.5 \\
\hline 500 & 268.08 & 168.0 & 280.9 & 400.1 & 53.29 & 0.190 & 0.027 & 0.935 & 180.4 & 360.5 \\
\hline
\end{tabular}


Table 3. Statistics of Bootstrap Replication for GLO Distribution (duration=24 hr)

\begin{tabular}{cccccccccccc}
\hline $\begin{array}{c}\text { Return } \\
\text { Period }\end{array}$ & Quantile & MIN & MEAN & MAX & SE & CV & $a_{1}$ & $a_{2}$ & LB & UB \\
\hline \hline 20 & 187.80 & 140.5 & 189.9 & 227.2 & 18.53 & 0.098 & 0.019 & 0.919 & 149.2 & 214.1 \\
\hline 30 & 204.11 & 144.6 & 206.6 & 250.4 & 22.91 & 0.111 & 0.022 & 0.925 & 157.1 & 239.2 \\
\hline 50 & 226.60 & 149.4 & 229.8 & 282.5 & 29.77 & 0.130 & 0.021 & 0.924 & 166.6 & 267.6 \\
\hline 80 & 249.49 & 153.6 & 253.7 & 324.2 & 37.68 & 0.149 & 0.014 & 0.908 & 172.0 & 300.5 \\
\hline 100 & 261.18 & 155.4 & 266.0 & 346.7 & 42.05 & 0.158 & 0.014 & 0.908 & 175.6 & 320.7 \\
\hline 200 & 301.29 & 161.0 & 308.7 & 431.2 & 58.74 & 0.190 & 0.014 & 0.908 & 186.1 & 387.9 \\
\hline 500 & 364.56 & 167.7 & 377.8 & 580.8 & 89.87 & 0.238 & 0.021 & 0.924 & 198.5 & 504.9 \\
\hline
\end{tabular}

Table 4. Quantile Estimates and BCa Intervals for GEV Distribution (Duration=24 hr)

\begin{tabular}{|c|c|c|c|c|c|}
\hline $\begin{array}{l}\text { Return Period } \\
\text { (year) } \\
\end{array}$ & $\begin{array}{l}\text { Quantile } \\
(\mathrm{mm}) \\
\end{array}$ & $a_{1}$ & $a_{2}$ & $\begin{array}{c}\text { Lower Bound } \\
(\mathrm{mm})\end{array}$ & $\begin{array}{l}\text { Upper Bound } \\
(\mathrm{mm})\end{array}$ \\
\hline 20 & 174.06 & 0.035 & 0.945 & 154.63 & 222.93 \\
\hline 30 & 189.24 & 0.027 & 0.934 & 159.73 & 246.85 \\
\hline 50 & 209.54 & 0.014 & 0.908 & 161.94 & 274.85 \\
\hline 80 & 229.48 & 0.018 & 0.918 & 166.40 & 305.56 \\
\hline 100 & 239.41 & 0.018 & 0.917 & 167.59 & 321.07 \\
\hline 200 & 272.28 & 0.022 & 0.926 & 171.18 & 372.18 \\
\hline 500 & 320.98 & 0.020 & 0.922 & 175.58 & 445.31 \\
\hline
\end{tabular}

Table 5. Quantile Estimates and BCa Intervals for Weibull Distribution (Duration=24 hr)

\begin{tabular}{|c|c|c|c|c|c|}
\hline $\begin{array}{l}\text { Return Period } \\
\text { (year) }\end{array}$ & $\begin{array}{l}\text { Quantile } \\
(\mathrm{mm}) \\
\end{array}$ & $a_{1}$ & $a_{2}$ & $\begin{array}{l}\text { Lower Bound } \\
(\mathrm{mm})\end{array}$ & $\begin{array}{l}\text { Upper Bound } \\
(\mathrm{mm})\end{array}$ \\
\hline 20 & 175.38 & 0.038 & 0.949 & 153.09 & 224.71 \\
\hline 30 & 187.80 & 0.034 & 0.944 & 157.34 & 245.07 \\
\hline 50 & 203.08 & 0.031 & 0.940 & 162.20 & 265.37 \\
\hline 80 & 216.81 & 0.033 & 0.943 & 166.41 & 288.08 \\
\hline 100 & 223.24 & 0.030 & 0.939 & 168.34 & 297.62 \\
\hline 200 & 242.85 & 0.030 & 0.939 & 173.94 & 324.54 \\
\hline 500 & 268.08 & 0.027 & 0.935 & 180.39 & 360.46 \\
\hline
\end{tabular}

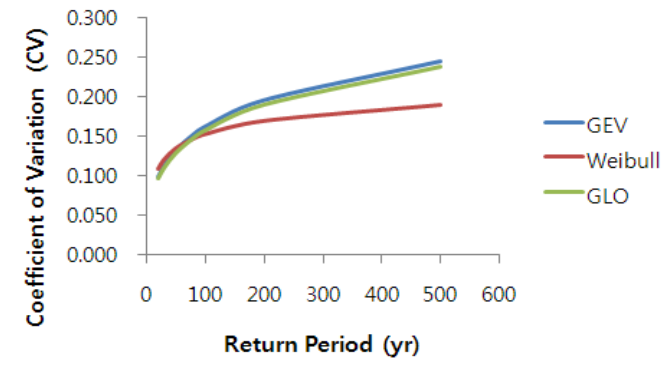

(a) Coefficient of Variation

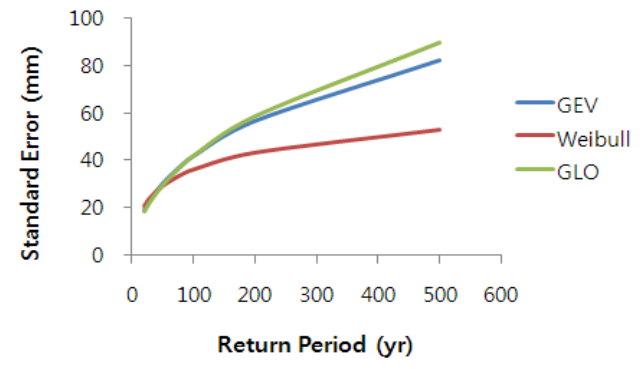

(b) Standard Error

Fig. 4. Coefficienct of Variation and Standard Error. (Duration $24 \mathrm{hr}$ )

가하는 경향을 나타내고 있음을 알 수 있다. 특히 $\mathrm{GLO}$ 및 $\mathrm{GEV}$ 분포의 경우 표준오차는 각각 18.53 $89.87 \mathrm{~mm}, 19.14 \sim 82.23 \mathrm{~mm}$, 변동계수는 각각 0.09 $8 \sim 0.238,0.100 \sim 0.246$ 의 변동성을 나타내고 있고 Weibull 분포의 경우 표준오차 및 변동계수는 각각
$20.99 \sim 53.29 \mathrm{~mm}, 0.110 \sim 0.190$ 의 변동성을 나타내 고 있어 Weibull 분포로부터의 Bootstrap 추정치가 세 확률분포형 중 가장 낮은 변동성을 나타냄을 확인할 수 있으며, Bootstrap 추정치의 변동성 측면에서는 가 장 낮은 변동성을 나타내는 Weibull 분포가 가장 적합 
한 확률분포형이라고 할 수 있다.

그러나 매개변수의 적합성 및 확률분포형의 적합 도 검정 결과는 $\mathrm{GLO}, \mathrm{GEV}$ 및 Weibull 분포의 순으로 적합도 순위가 분석되었기 때문에 적합도 검정 및 변 동성 분석결과를 종합적으로 판단하여 대표확률분포 형을 선정해야 할 것으로 판단된다. 또한 변동성 분석 결과에서 각 확률분포형간 변동성의 차이는 재현기간 이 증가할수록(특히 100 년 이상) 그 차이가 더욱 커지 는 것을 확인할 수 있으며, Weibull 분포의 경우 재현 기간의 증가에 따른 변동성의 증가율이 다른 확률분 포형에 비해 낮게 나타나는 결과로부터 재현기간 100
년 이상의 확률강우량 추정시 확률분포형 선정에 따 른 확률강우량의 불확실성에 대한 영향이 매우 큼을 확인할 수 있다. 위천의 경우 100 년 빈도의 확률강우 량의 경우 불확실성이 가장 작게 산정된 Weibull 분포 에서 지속시간 24 시간의 확률강우량이 $223.24 \mathrm{~mm}$ 로 추정되었으며, 상-하한의 경우 168.34 297.62 mm로 추정이 되었다.

한편, Table 4 6 및 Fig. 5 로부터 각 확률분포형별 $\mathrm{BCa}$ 신뢰구간 산정결과를 살펴보면 재현기간이 증가 함에 따라 $\mathrm{BCa}$ 신뢰구간의 크기가 증가하는 경향을 나타내고 있음을 알 수 있다. 지속시간 24시간, 재현

Table 6. Quantile Estimates and BCa Intervals for GLO Distribution (Duration=24 hr)

\begin{tabular}{|c|c|c|c|c|c|}
\hline $\begin{array}{l}\text { Return Period } \\
\text { (year) }\end{array}$ & $\begin{array}{l}\text { Quantile } \\
(\mathrm{mm})\end{array}$ & $a_{1}$ & $a_{2}$ & $\begin{array}{l}\text { Lower Bound } \\
(\mathrm{mm})\end{array}$ & $\begin{array}{l}\text { Upper Bound } \\
(\mathrm{mm})\end{array}$ \\
\hline 20 & 187.80 & 0.019 & 0.919 & 149.20 & 214.09 \\
\hline 30 & 204.11 & 0.022 & 0.925 & 157.08 & 239.16 \\
\hline 50 & 226.60 & 0.021 & 0.924 & 166.63 & 267.60 \\
\hline 80 & 249.49 & 0.014 & 0.908 & 172.04 & 300.46 \\
\hline 100 & 261.18 & 0.014 & 0.908 & 175.56 & 320.65 \\
\hline 200 & 301.29 & 0.014 & 0.908 & 186.14 & 387.88 \\
\hline 500 & 364.56 & 0.021 & 0.924 & 198.52 & 504.95 \\
\hline
\end{tabular}

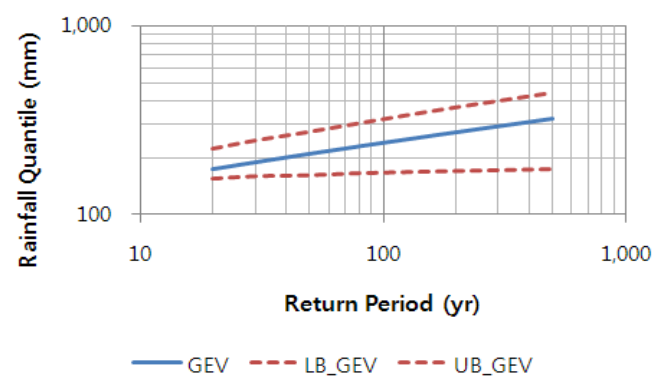

(a) GEV Distribution

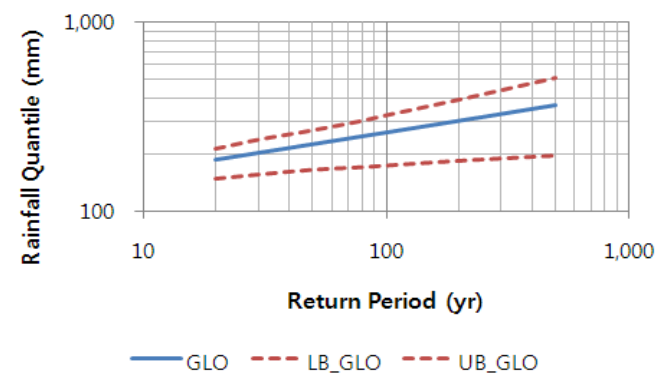

(c) GLO Distribution

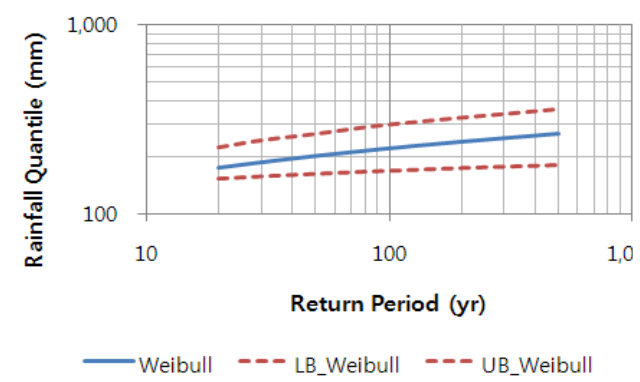

(b) Weibull Distribution

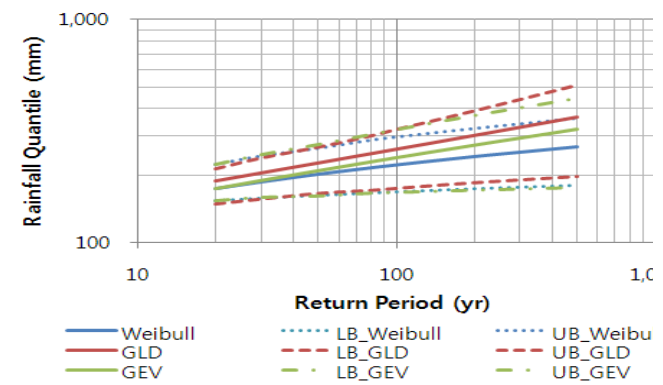

(d) GEV, Weibull and GLO Distribution

Fig. 5. Quantile Estimates and BCa Intervals. (Duration $24 \mathrm{hr}$ ) 
기간 100 년을 기준으로 각 확률분포형별 $\mathrm{BCa}$ 신뢰구 간 또는 불확실성 범위를 살펴보면 $\mathrm{GLO}, \mathrm{GEV}$ 및 Weibull 분포가 각각 $145.09,153.48$ 및 $129.28 \mathrm{~mm}$ 로 분석되었으며, Weibull 분포의 확률강우량에 대한 불 확실성 범위가 가장 작고 GLO 분포의 불확실성 범위 가 가장 크게 나타남을 확인할 수 있다.

확률강우량의 불확실성 범위는 그 크기가 작을수 록 신뢰성 있는 추정결과가 될 수 있고 이러한 결과를 향후 강우유출분석 및 홍수위분석 등에 적용하여 불 확실성을 전파시킬 경우 그 분석결과에 따른 불확실 성의 범위는 더욱 증가할 것으로 예상되기 때문에 확 룰강우량에 대한 불확실성 범위 또는 $\mathrm{BCa}$ 신뢰구간 의 크기가 상대적으로 작은 확률분포형이 선정되어야 할 것이며, 본 연구에서는 확률분포형의 매개변수 추 정기법으로 L-moment 법만을 적용하였으나 다른 추 정기법과의 비교를 통해 확률강우량에 대한 불확실성 범위가 상대적으로 작게 추정되는 매개변수 추정기법 을 선정해야 할 것으로 판단된다.

\section{4. 결 론}

본 연구에서는 강우빈도해석에서 확률분포의 매개 변수 추정에 대한 불확실성 고려한 확률강우량의 산정 및 불확실성의 영향을 평가하기 위하여 Bootstrap 기법 에 기반한 불확실성을 고려한 강우빈도해석모델 구축 및 적용을 실시하였으며, 다음과 같은 결론을 얻었다.

1) 강우빈도해석에서 확률분포의 매개변수 추정에 대 한 불확실성을 분석하기 위해 Bootstrap 기법에 기 반한 불확실성 평가모델을 구축하였으며, 이를 확 률분포의 매개변수 추정기법인 L-moment법과 결 합하여 매개변수의 불확실성을 고려한 확률강우량 을 산정모델을 제시하였다.

2) 확률분포형의 매개변수에 대한 불확실성을 고려한 Bootstrap 기법의 적용을 통해 매개변수의 적합성 및 확률분포형의 적합도 검정, Bootstrap 추정치의 표준오차 및 변동계수를 종합적으로 고려하여 대 표 확률분포형을 선정하는 기법을 제시하였다. 본
연구 대상유역인 위천유역의 경우 100 년 빈도의 지 속시간 24시간에 대한 분석결과로서 Weibull 분포 가 가장 불확실성이 적은 것으로 나타났으며, 표준 오차(SE)와 변동계수 $(\mathrm{CV})$ 가 가장 작게 나타났다. 또한 확률강우량의 경우 $223.24 \mathrm{~mm}$ 로 추정되었 으며, 상-하한의 경우 $168.34 \sim 297.62 \mathrm{~mm}$ 로 분석되 어 가장 오차범위가 좁게 나타났다.

3) 따라서 본 연구에서 재현기간별 확률강우량의 $\mathrm{BCa}$ 신뢰구간의 추정을 통해 매개변수의 불확실성에 따른 확률강우량의 불확실성 범위를 산정하여 가 장 좁은 범위를 나타낼 수 있는 방법을 제시하여 확 률강우량의 불확실성 범위를 정량적으로 제시하는 방안을 제시하고 그 적용을 통해 확률강우량 추정 에 대한 불확실성 해석에서 $\mathrm{BCa}$ 기법의 적용성을 확인할 수 있었다.

\section{참 고 문 헌}

서영민, 지홍기, 이순탁, 2009a, Bootstrap을 이용한 강우 빈도해석에서의 매개변수 추정에 대한 불확실성 해 석, 한국수자원학회 학술발표회 논문집, 299.

서영민, 지홍기, 이순탁, $2009 \mathrm{~b}$, 강우빈도분석에서 확률 분포형의 매개변수 추정시 불확실성 해석에 대한 Bootstap 기법의 적용, 대한토목학회 학술발표회 초 록집, 65 .

문기호, 경민수, 김형수, 2010, 극한강우를 고려한 SIR알 고리즘과 Bootstrap을 활용한 강우빈도해석, 대한토 목학회논문집, 30(4B), 367-377.

DiCiccio, T. J., Efron, B., 1996, Bootstrap Confidence Intervals, Statistical Science, 11( 3), 189-228.

Dunn, P. K., 2001, Bootstrap Confidence Intervals for Predicted Rainfall Quantiles, International Journal of Climatology, 21, 89-94.

Efron, B., 2003, Second Thoughts on the Bootstrap, Statistical Science, 18(2), 135-140.

Efron, B., Tibshirani, R. J., 1994, An Introduction to the Bootstrap, Chapman \& Hall/CRC.

Rao, A. R., Hamed, K. H., 2000, Flood Frequency Analysis, CRC Press LLC. 